\title{
Applying Graph Coloring To Schedule Doctors' Work In A Hospital.
}

\author{
Ferdous M O Tawfiq, Kholoud Khalid S Al-qahtani \\ King Saud University (KSU), Saudi Arabia, Riyadh \\ ftoufic@ksu.edu.sa \\ King Saud University (KSU), Saudi Arabia, Riyadh \\ 432201096@student.ksu.edu.sa
}

\begin{abstract}
Scheduling shifts is a tiresome and time consuming task in any business, and particularly in hospitals where errors are costly, rules are plentiful and changes are rapid. The person performing this function (Rota Organizer) will have to keep track of all the employees concerned, distributing hours fairly and avoiding collisions. Rules regulating working hours and breaks have to be followed and the qualifications of individual employees need to be considered. Hours are spent every day on this task in every ward. The goal of this paper is to solve Doctors Scheduling Problem (DSP) and initialize a fair roster for two wards of Pediatric Department (PD) in Prince Sultan Military Medical City (PSMMC) in Saudi Arabia. So to find a solution of DSP, we used Graph Coloring which is one of the methods used mostly to solve this problem.
\end{abstract}

\section{Indexing terms/Keywords}

Graph coloring; doctor's roster; greedy algorithm.

\section{Academic Discipline And Sub-Disciplines}

Mathematics- Discrete;

\section{SUBJECT CLASSIFICATION}

2010 Mathematics Subject Classification. 18C10, 18C50, 68Q55, 68Q65, 03B70, 06B35

\section{TYPE (METHOD/APPROACH)}

\author{
Graph Theory/ coloring
}

\section{INTRODUCTION}

In the study of graphs, which are mathematical structures used to model pair wise relations between objects. A "graph" is made up of vertices (or nodes) and lines called edges that connect them.

Graphs can be used to model many types of relations and processes in physical, biological, social and information systems. Graph coloring has been studied extensively for the past decades. The surge for studying graph coloring in recent times has resulted in countless real-life problem applications, which include scheduling problems. Research presented in this paper aims to provide an effective procedure for solving Doctors Scheduling Problem (DSP) related to their shifts. DSP is a major problem faced by many hospitals all over the world. We tried in two wards of PSMMC to establish a roster for one month as a beginning to achieve a general procedure for every month. After exploring relevant references the problem will be described in details, followed by the formulation of relevant coloring problem and its solution with recent results.

\section{STATEMENT OF THE PROBLEM}

In this paper, we shall consider a scheduling problem for Pediatric Department of Prince Sultan Military Medical City (PSMMC) in Riyadh/ Saudi Arabia. It is considered one of the top governmental hospitals with almost twenty seven departments. There are more than five thousand doctors in the hospital. We communicated with Dr. Nawaf Al khayat (Dr.N.A.,) in PD of PSMMIC; he is a consultant and supervisor of resident doctors training in PSMMIC.

Usually, monthly doctors roster are made manually before the end of each month. Rota organizer has the responsibility to publish next month's roster. Even though making monthly rosters manually requires great effort, it does not resolve all conflicts. Instead, it has created more tedious adjustments to accomplish needed tasks. There are consultants, senior and junior doctors working in this department. This paper is concerned with scheduling shifts for junior and senior doctors in two of the department wards for one month only.

There are three types of doctors: Consultants, Seniors (R3 \& R4) and Juniors (R1 \& R2), where number indicates trainee year. In PSMMC pediatric department, which has thirteen wards, there are thirty eight resident doctors; R1, R2, R3 and R4. It has been specified for us to work on scheduling shifts for only two wards: PG (Pediatrics General) and PGICU (Pediatrics General Intensive Care Unit) wards. In addition, we were given the following information: 
1. Each working day consists of eight to eight and half hours.

2. Each shift consists of twenty four hours.

3. Every doctor who has participated in a shift will not be given anther shift for the next three days.

4. There are twenty two junior and sixteen senior doctors.

5. In each working month there are doctors who are excluded from participating in shifts due to other responsibilities or personal circumstances.

We chose September 2016 to be the month we consider for scheduling. In September, only eighteen doctors are excluded which is the least number of doctors among other remaining months. From list of names given to us by Dr.N.A., we have listed doctors who will participate in September shifts (S.S.). There are twelve juniors and eight seniors available. In the proposed solution for DSP (Doctors Scheduling Problem), we need to assign doctors into shifts.

\section{FORMULATION OF A GRAPH COLORING PROBLEM}

First, we divided doctors into four shift groups. Each group has two seniors and four juniors based on department daily requirement, and the fact that we only have twelve juniors and eight seniors in this month. Since both PG and PGICU involved doctors cannot accomplished needed shifts while meeting restrictions of the department, we had several options.

We chose to involve one doctor outside PG and PGICU, each day of September to complement needed shifts. So we had $A, B, C$ and $D$ groups to cover first four consecutive days which will represent the same groups for the following fourdays, and so on. This implies a need for additional four juniors \{SUB.1, SUB.2, SUB.3, SUB.4\}, (SUB.1 refer to first substitute for a junior), to complement required number of doctors ( 8 senior and 16 juniors in conditions 3 above).

Table 1. Groups of September schedule doctors(S.S.D.)

\begin{tabular}{|c|c|}
\hline Group & Doctors \\
\hline $\mathrm{A}$ & $R 3_{1}, R 4_{1}, R 1_{1}, R 1_{5}, R 2_{4}, S U B_{1}$. \\
\hline $\mathrm{B}$ & $R 3_{2}, R 4_{2}, R 1_{2}, R 2_{1}, R 2_{5}, S U B_{2}$. \\
\hline $\mathrm{C}$ & $R 3_{3}, R 4_{3}, R 1_{3}, R 2_{2}, R 2_{6}, S U B_{3}$. \\
\hline $\mathrm{D}$ & $R 3_{4}, R 4_{4}, R 1_{4}, R 2_{3}, R 2_{7}, S U B_{4}$ \\
\hline
\end{tabular}

By using above data an incident matrix is initiated for S.S.D. It is a $24 \times 24$ matrix. If any two doctors are in same group then ij-th entry is 1 otherwis it is 0 . By using the incident matrix a graph is constructed with S.S.D. as vertices. If two doctors are in same group then they are linked with an edge. Next, we colored the graph by using Greedy algorithm. We started with red as color number one and take color number two to be yellow. Color number three is gray, also color number four is orange and color number five is green, we needed six colors, so the last color is going to be blue.

Now we will start with vertices representing seniors; first senior each day will be colored by red. The second senior adjacent to first one will be colored yellow. Since every day there are four juniors adjacent to each other and to the red and yellow seniors, the first one of these juniors every day will be colored gray, the second one is orange, third one green, and last one is blue. See Figure1.

Above we have included substitutes in the coloring scheme to organize needed shifts. This means first day group will be repeated in fifth day, second group will be repeated in sixth day, third group will be repeated in seventh day and fourth group will be repeated in eighth day. So, to finish up the process the cycle will be repeated every four day. 
Table 2. Groups After Applying Graph Coloring

\begin{tabular}{|c|c|}
\hline Group & Doctors \\
\hline$G 1$ & $R 3_{4}, R 4_{2}, R 4_{3}, R 3_{1}$ \\
\hline$G 2$ & $R 4_{1}, R 4_{4}, R 3_{3}, R 3_{2}$ \\
\hline$G 3$ & $R 1_{4}, R 1_{2}, R 1_{1}, S U B_{3}$ \\
\hline$G 4$ & $R 1_{5}, R 2_{5}, S U B_{4}, R 2_{6}$ \\
\hline$G 5$ & $R 2_{4}, R 1_{3}, S U B_{2}, R 2_{7}$ \\
\hline$G 6$ & $R 2_{3}, R 2_{2}, R 2_{1}, S U B_{1}$ \\
\hline
\end{tabular}

Accordingly we formulated a table where S.S.D. doctors in $\mathrm{G} 1, \mathrm{G} 2 \ldots \mathrm{G} 6$ should be in the same ward if they are in the same group. Based on restrictions specified in Section 3 concerning the problem of making doctors roster for September 2016 in PD of PSMMC, we have divided doctors into shifts groups.

Then, we applied the graph theory to these groups so that each vertex represents a doctor and there is an edge between any two doctors in one shift group, see section 2 for details.

After graphing, we used Greedy Algorithm to color. We used six colors for twenty four vertices, where each four vertices have one color.

In the graph, doctors represented by vertices of the same color are grouped as one since they will be working in the same ward. The shift groups (Table1) are then used to form a $24 \times 2$ matrix elements of first columns represent numbering of doctors and element of second column represent colors of these doctors which are numbering like that ( 1 is red, 2 is yellow, 3 is gray, 4 is orange, 5 is green and 6 is blue). We used this matrix to create code by Matlab. The output of this code is distribution in the wards.

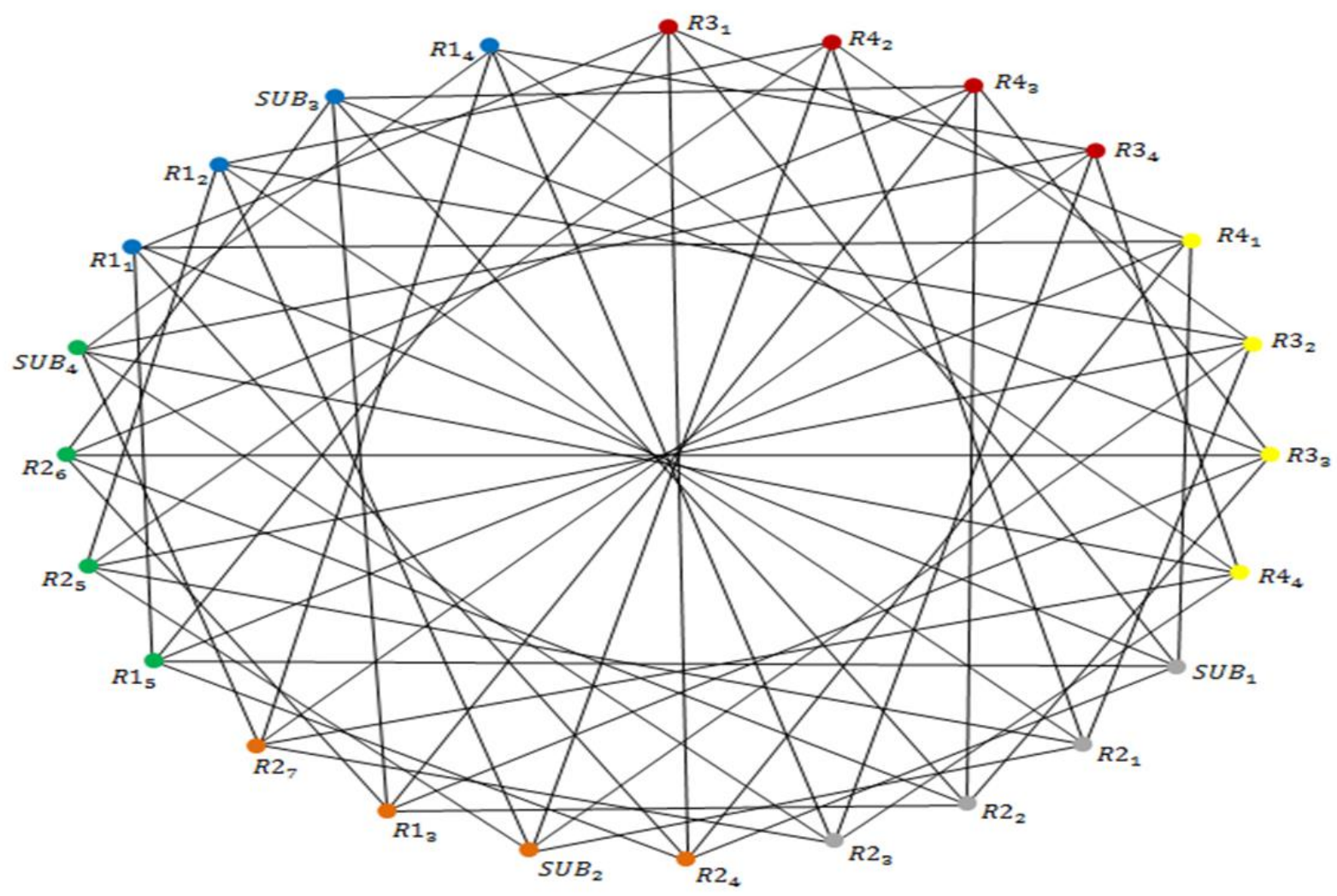

Fig 1: A Colored Graph of The Doctors 


\section{RESULTS}

The table3 shows the first phase of result: distribution of doctors in wards. We note that each element represents the participation of specific doctor in a shift, i.e.,

\section{$\left\{\begin{array}{l}1 \text { if doctor is alternating. } \\ 0 \text { if doctor is not alternating. }\end{array}\right.$}

Table 3. Distribution of Doctors in Wards After converting Result From Matlab

\begin{tabular}{|c|c|c|c|c|c|}
\hline $\mathbf{A}$ & $\mathbf{B}$ & $\mathbf{C}$ & $\mathbf{D}$ & $\mathbf{E}$ & $\mathbf{F}$ \\
\hline$R 3_{1}$ & $R 4_{1}$ & $S U B_{1}$ & $R 2_{4}$ & $R 1_{5}$ & $R 1_{1}$ \\
\hline$R 4_{2}$ & $R 3_{2}$ & $R 2_{1}$ & $S U B_{2}$ & $R 2_{5}$ & $R 1_{2}$ \\
\hline$R 4_{3}$ & $R 3_{3}$ & $R 2_{2}$ & $R 1_{3}$ & $R 2_{6}$ & $S U B_{3}$ \\
\hline$R 3_{4}$ & $R 4_{4}$ & $R 2_{3}$ & $R 2_{7}$ & $S U B_{4}$ & $R 1_{4}$ \\
\hline
\end{tabular}

In this paper, we have finalized a roster for September 2016 shifts of two wards PG and PGICU in PD of PSMMC. This roster has taken into consideration departmental restrictions in doing so, we are hoping to have saved PG and PGICU from getting into misunderstandings, as well as any other relevant troubles. Instead of consuming time and effort to generate doctors roster, the staff can concentrate on other important medical duties.

At the end, we can confirm that steps leading to a roster of September 2016 as detailed in section 3, can be used and applied for other months, nurses as well as doctors.

Table 4. The Final Roster For The PD

\begin{tabular}{|c|c|c|c|c|c|c|c|}
\hline Date & Day & A & B & C & D & $E$ & $F$ \\
\hline 4 Sep. & Sun. & $\mathrm{R} 3_{1}$ & $\mathrm{R} 4_{1}$ & $\mathrm{SUB}_{1}$ & $\mathrm{R} 2_{4}$ & $\mathrm{R} 1_{5}$ & $\mathrm{R} 1_{1}$ \\
\hline 5 & Mon. & $\mathrm{R}_{4}$ & $\mathrm{R}_{2}$ & $\mathrm{R} 2_{1}$ & $\mathrm{SUB}_{2}$ & $\mathrm{R} 2_{5}$ & $\mathrm{R} 1_{2}$ \\
\hline 6 & Tue. & $\mathrm{R}_{3}$ & $\mathrm{R}_{3}$ & $\mathrm{R} 2_{2}$ & $\mathrm{R} 1_{3}$ & $\mathrm{R} 2_{6}$ & $\mathrm{SUB}_{3}$ \\
\hline 7 & Wed. & $\mathrm{R}_{4}$ & $\mathrm{R} 4_{4}$ & $\mathrm{R} 2_{3}$ & $\mathrm{R} 2_{7}$ & $\mathrm{SUB}_{4}$ & $\mathrm{R} 1_{4}$ \\
\hline 8 & Thu. & $\mathrm{R} 3_{1}$ & $\mathrm{R} 4_{1}$ & $\mathrm{SUB}_{1}$ & $\mathrm{R} 2_{4}$ & $\mathrm{R} 1_{5}$ & $\mathrm{R} 1_{1}$ \\
\hline 9 & Fri. & $\mathrm{R}_{4}$ & $\mathrm{R}_{2}$ & $\mathrm{R} 2_{1}$ & $\mathrm{SUB}_{2}$ & $\mathrm{R} 2_{5}$ & $\mathrm{R} 1_{2}$ \\
\hline 10 & Sat. & $\mathrm{R}_{4}$ & $\mathrm{R}_{3}$ & $\mathrm{R} 2_{2}$ & $\mathrm{R} 1_{3}$ & $\mathrm{R} 2_{6}$ & $\mathrm{SUB}_{3}$ \\
\hline 11 & Sun. & $\mathrm{R} 3_{4}$ & $\mathrm{R} 4_{4}$ & $\mathrm{R} 2_{3}$ & $\mathrm{R} 2_{7}$ & $\mathrm{SUB}_{4}$ & $\mathrm{R} 1_{4}$ \\
\hline 12 & Mon. & $\mathrm{R} 3_{1}$ & $\mathrm{R} 4_{1}$ & $\mathrm{SUB}_{1}$ & $\mathrm{R} 2_{4}$ & $\mathrm{R} 1_{5}$ & $\mathrm{R} 1_{1}$ \\
\hline 13 & Tue. & $\mathrm{R} 4_{2}$ & $\mathrm{R} 3_{2}$ & $\mathrm{R} 2_{1}$ & $\mathrm{SUB}_{2}$ & $\mathrm{R} 2_{5}$ & $\mathrm{R} 1_{2}$ \\
\hline 14 & Wed. & $\mathrm{R}_{4}$ & $\mathrm{R}_{3}$ & $\mathrm{R} 2_{2}$ & $\mathrm{R} 1_{3}$ & $\mathrm{R} 2_{6}$ & $\mathrm{SUB}_{3}$ \\
\hline 15 & Thu. & $\mathrm{R} 3_{4}$ & $\mathrm{R} 4_{4}$ & $\mathrm{R} 2_{3}$ & $\mathrm{R} 2_{7}$ & $\mathrm{SUB}_{4}$ & $\mathrm{R} 1_{4}$ \\
\hline 16 & Fri. & $\mathrm{R} 3_{1}$ & $\mathrm{R} 4_{1}$ & $\mathrm{SUB}_{1}$ & $\mathrm{R} 2_{4}$ & $\mathrm{R} 1_{5}$ & $\mathrm{R} 1_{1}$ \\
\hline 17 & Sat. & $\mathrm{R} 4_{2}$ & $\mathrm{R}_{2}$ & $\mathrm{R} 2_{1}$ & $\mathrm{SUB}_{2}$ & $\mathrm{R} 2_{5}$ & $\mathrm{R} 1_{2}$ \\
\hline 18 & Sun. & $\mathrm{R}_{4}$ & $\mathrm{R}_{3}$ & $\mathrm{R} 2_{2}$ & $\mathrm{R} 1_{3}$ & $\mathrm{R} 2_{6}$ & $\mathrm{SUB}_{3}$ \\
\hline 19 & Mon. & $\mathrm{R}_{4}$ & $\mathrm{R} 4_{4}$ & $\mathrm{R} 2_{3}$ & $\mathrm{R} 2_{7}$ & $\mathrm{SUB}_{4}$ & $\mathrm{R} 1_{4}$ \\
\hline 20 & Tue. & $\mathrm{R} 3_{1}$ & $\mathrm{R} 4_{1}$ & $\mathrm{SUB}_{1}$ & $\mathrm{R} 2_{4}$ & $\mathrm{R} 1_{5}$ & $\mathrm{R} 1_{1}$ \\
\hline 21 & Wed. & $\mathrm{R} 4_{2}$ & $\mathrm{R} 3_{2}$ & $\mathrm{R} 2_{1}$ & $\mathrm{SUB}_{2}$ & $\mathrm{R} 2{ }_{5}$ & $\mathrm{R} 1_{2}$ \\
\hline 22 & Thu. & $\mathrm{R}_{3}$ & $\mathrm{R}_{3}$ & $\mathrm{R} 2_{2}$ & $\mathrm{R} 1_{3}$ & $\mathrm{R} 2_{6}$ & $\mathrm{SUB}_{3}$ \\
\hline
\end{tabular}




\begin{tabular}{|c|c|c|c|c|c|c|c|}
\hline 23 & Fri. & $\mathrm{R} 3_{4}$ & $\mathrm{R}_{4}$ & $\mathrm{R} 2_{3}$ & $\mathrm{R} 2_{7}$ & $\mathrm{SUB}_{4}$ & $\mathrm{R} 1_{4}$ \\
\hline 24 & Sat. & $\mathrm{R} 3_{1}$ & $\mathrm{R} 4_{1}$ & $\mathrm{SUB}_{1}$ & $\mathrm{R} 2_{4}$ & $\mathrm{R} 1_{5}$ & $\mathrm{R} 1_{1}$ \\
\hline 25 & Sun. & $\mathrm{R} 4_{2}$ & $\mathrm{R} 3_{2}$ & $\mathrm{R} 2_{1}$ & $\mathrm{SUB}_{2}$ & $\mathrm{R} 2_{5}$ & $\mathrm{R} 1_{2}$ \\
\hline 26 & Mon. & $\mathrm{R} 4_{3}$ & $\mathrm{R} 3_{3}$ & $\mathrm{R} 2_{2}$ & $\mathrm{R} 1_{3}$ & $\mathrm{R} 2_{6}$ & $\mathrm{SUB}_{3}$ \\
\hline 27 & Tue. & $\mathrm{R} 3_{4}$ & $\mathrm{R} 4_{4}$ & $\mathrm{R} 2_{3}$ & $\mathrm{R} 2_{7}$ & $\mathrm{SUB}_{4}$ & $\mathrm{R} 1_{4}$ \\
\hline 28 & Wed. & $\mathrm{R} 3_{1}$ & $\mathrm{R} 4_{1}$ & $\mathrm{SUB}_{1}$ & $\mathrm{R} 2_{4}$ & $\mathrm{R} 1_{5}$ & $\mathrm{R} 1_{1}$ \\
\hline 29 & Thu. & $\mathrm{R} 4_{2}$ & $\mathrm{R} 3_{2}$ & $\mathrm{R} 2_{1}$ & $\mathrm{SUB}_{2}$ & $\mathrm{R} 2_{5}$ & $\mathrm{R} 1_{2}$ \\
\hline 30 & Fri. & $\mathrm{R} 4_{3}$ & $\mathrm{R} 3_{3}$ & $\mathrm{R} 2_{2}$ & $\mathrm{R} 1_{3}$ & $\mathrm{R} 2_{6}$ & $\mathrm{SUB}_{3}$ \\
\hline 1 Oct. & Sat. & $\mathrm{R} 3_{4}$ & $\mathrm{R}_{4}$ & $\mathrm{R} 2_{3}$ & $\mathrm{R} 2_{7}$ & $\mathrm{SUB}_{4}$ & $\mathrm{R} 1_{4}$ \\
\hline
\end{tabular}

\section{FUTURE WORK}

Many hospitals take a long time to prepare doctors roster, which is fair to everybody. Instead of consuming time in generating it, we hope to generalize in future work a software, where minimum data is required to have a roster for any month.

\section{ACKNOWLEDGMENTS}

Thanks to Deanship of Scientific Research at King Saud University (KSU) for funding this work through undergraduate students research support program project on (USRSP).

\section{REFERENCES}

1. Amponsah, S.K, Agyeman, E., Okran, K.G. 2011. Graph Coloring, an Approach to Nurses Scheduling. AmericanEurasian Journal of Scientific Research 6(1). Ghana, 1-5.

2. Butt, R. 2007. Introduction to Numerical Analysis Using Matlab. USA.

3. Diestel, R. 2000. Graph Theory. Springer-Verlag, New Your, 98-103.

4. Gideon, A. 2013. A Nurse Scheduling Using Graph Coloring. Master thesis submitted, Mathematics Department, Kwame Nkrumah University, Ghana, 1-4, 35, 53-77.

5. Harju, T. 2011. Graph Theory. Lecture Notes in Mathematics, Finland, 53-60.

6. Kumara, B.T.G.S., Perera, A.A.I. 2011. Automated System For Nurse Scheduling Using Graph Coloring. Indian Journal of Computer Science and Engineering (IJCSE), 476- 485.

7. Rosen, K. 2012. Discrete Mathematics and It's Applications. New York.

8. Rosen, K. 2009. Chromatic Graph Theory. Michigan.

9. Shekhar, S. 2012. Graph Theory. Lecture Notes in Mathematics, US, 137-139.

10. Skogvold, A.; Saether, T.; Moseby, S.; Westby, P. 2009. Flexible Duty Roster for Doctors in Hospital, 1-3.

11. West, D. 2001. Introduction to Graph Theory. New Jesey.

12. Wilson, R. 1996. Introduction to Graph Theory. England.

13. Wren, A., Scheduling. 1996. Timetabling and Rostering- a Special Relationship?. Lecture Notes in Computer Science. Springer-verlag, Berlin, 46-75.

14. Dharwardker,A., 2006. The Vertex Coloring Algorithm. Available at: <http://www.dharwadker.org/vertex_colorin g/>, (March 2016).

15. Greedy Coloring Algorithm. August 2015. Available at: < https://www.youtube.com/watch?v=vGjsi8 NIpSE >, (May 2015).

\section{Author' biography}

